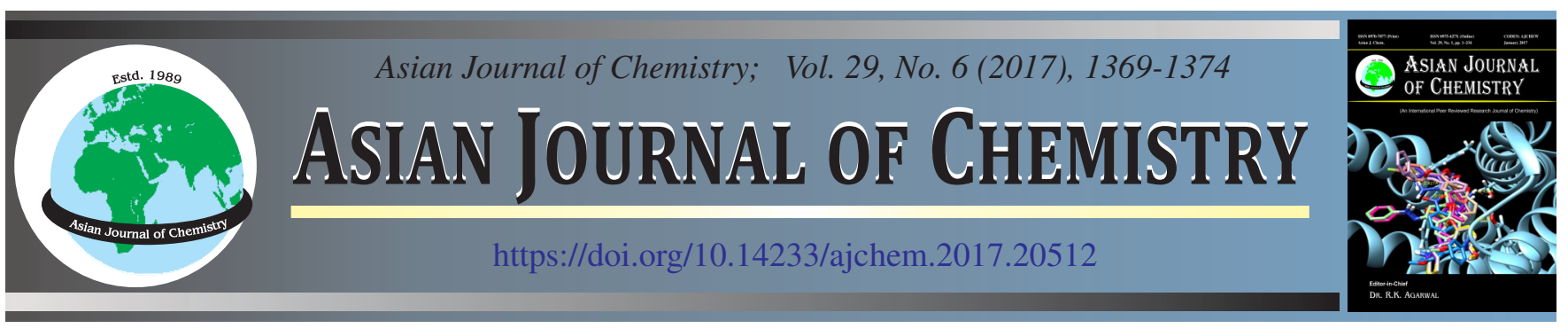

\title{
Structural, Optical and Laser Damage Threshold Studies of Polarizable Organic Crystal: 4-Methylpyridinium Picrate
}

\author{
D. Shalini, V. Revathi Ambika, N. Hema, R. Usha and D. Jayalakshmi*
}

PG and Research Department of Physics, Queen Mary's College (A), Chennai-600 004, India

*Corresponding author: E-mail: djayalakshmi2016@gmail.com

Received: 11 January 2017;

Accepted: 28 February 2017;

Published online: 10 April 2017;

AJC-18357

\begin{abstract}
New organic material has been synthesized and single crystals were grown from aqueous solution. Single crystals of 4-methylpyridinium picrate have been grown by slow evaporation technique acetone as a solvent at room temperature. Single crystal X-ray diffraction study on grown crystals shows that it belongs to monoclinic system. Fourier transform infrared (FTIR) spectroscopic study was performed for the identification of different modes of functional groups present in the compound. The thermal stability of the compound has been determined by TG-DTA curves. The result shows that the material starts decomposing at $171.50{ }^{\circ} \mathrm{C}$. The UV-visible transmission spectrum has been recorded in the range 190-900 $\mathrm{nm}$. The photoconductivity study confirms the negative photoconductive nature of the sample. The dielectric measurement of the compound has been analyzed using dielectric analysis. Laser damage threshold value for the crystal was measured.
\end{abstract}

Keywords: 4-Methylpyridinium picrate, Monoclinic, Transmission, Laser damage threshold.

\section{INTRODUCTION}

The crystalline material is very essential for the expansion of non-linear optical field and the continuous detection of different effective and well-organized nonlinear equipments. It encourages the wide applications of laser frequency conversion techniques in many areas [1]. Organic molecules containing donor and acceptor groups have new advantages over inorganic materials due to the possibility of enhanced electronic non-linear optical polarization response [2]. Hydrogen bonding defines the structure of the crystals so this plays an important role in molecular recognition and crystal engineering research [3]. Pyridine derivatives are present in large molecules that it allows us to obtain different substituents in any positions on the pyridine ring and several pyridine derivatives possess optical properties [4,5]. Picric acid forms crystalline picrates of different organic molecules through ionic and hydrogen bonding. In this work 4-methypyridinium picrate (4MPI) is one such donor acceptor molecular compound in which 4-methypyridinium acts as acceptor and the picric acid act as a donor.In the present investigation, we report synthesis, growth, structural, spectral, optical, dielectric and thermal properties of 4-methylpyridinium picrate single crystal.

\section{EXPERIMENTAL}

Growth process: The grown crystals were obtained by the method of slow evaporation technique at room temperature.
The 4-methylpyridine and picric acid taken in a 1:1 molar ratio. Picric acid is dissolved in $100 \mathrm{~mL}$ of acetone using magnetic stirrer, following which 4-methyl pyridine (Sigma Aldrich) solution is being added with drop by drop. The stirring is allowed up to $6 \mathrm{~h}$ to attain the saturation state of the solution. The prepared solution is filtered using Whatman filter paper and then the solution is kept at room temperature, without any disturbance from the environment. 4-Methylpyridinium picrate crystal has been obtained within 2-3 weeks and the grown crystal is allowed to recrystallization process to improve the optical quality of the crystal. The grown 4-methyl-pyridinium picrate crystal is shown in Fig. 1.

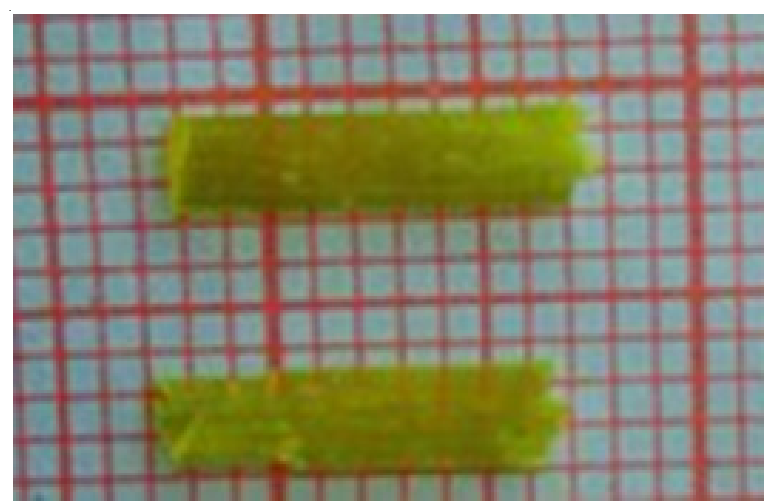

Fig. 1. As-grown crystal of 4-methylpyridinium picrate 
FT-IR: The FT-IR spectrum is recorded between 4000$400 \mathrm{~cm}^{-1}$ using $\mathrm{KBr}$ pellet technique by Bruker IFS 66V FTIR spectrometer.

Measurement of melting point: The melting point of 4methylpyridinium picrate compound is $159{ }^{\circ} \mathrm{C}$. The error of the measurement was $\pm 2{ }^{\circ} \mathrm{C}$.

Thermal analysis: Thermo gravimetric analysis (TGA) and differential thermal analysis (DTA) of grown crystals (4methylpyridinium picrate) were carried out simultaneously by employing TA instrument model Q600 SDT thermal analyzer. The sample was heated at the rate of $10^{\circ} \mathrm{C} / \mathrm{min}$ in inert nitrogen atmosphere.

UV-Vis-NIR analysis: The optical studies for 4-methylpyridinium picrate crystals were carried out using T-90+ Lab India UV-visible spectrophotometer in the range 190-900 nm.

X-ray diffraction analysis: The crystal of 4-methylpyridinium picrate was confirmed by single crystal X-ray diffraction analysis using Bruker kappa APEXII single crystal $\mathrm{X}$-ray diffractometer with graphite monochromated MoK $\alpha$ radiation $(\lambda=0.71073 \AA)$ at $296 \mathrm{~K}$.

Refractive index measurement: Polished crystals of the 4-methylpyridinium picrate were used for refractive index measurements. These crystals were placed on a rotating mount at an angle from 0 to $90^{\circ}$. He-Ne laser of wavelength $632.8 \mathrm{~nm}$ was used as the source. Brewster's angle $(\theta p)$ for 4-methylpyridinium picrate was measured to be $56.6^{\circ}$. The refractive index has been calculated using the equation $n=\tan \theta p$, where $\theta p$ is the polarizing angle and it is found to be 1.52 .

Photoconductivity studies: The photoconductivity studies of the grown crystals were carried out by connecting the sample in series with a DC power supply and a pico ammeter (Kiethley 485 ) at room temperature. The crystal was covered with a black cloth and the applied voltage was increased from 0 to 300 Volts in steps of 20 Volt and the dark current was recorded. The sample was illuminated by the radiation from $100 \mathrm{~W}$ halogen lamp containing iodine vapour and tungsten filament. The photocurrent was recorded for the same values of the applied voltage.

Dielectric analysis: Good quality single crystals of 4methylpyridinium picrate crystal were selected for the dielectric measurements using HIOKI3532-50 LCR HITESTER in the frequency range of $50 \mathrm{~Hz}$ to $5 \mathrm{MHz}$ at various temperatures like 40, 50, 60 and $70{ }^{\circ} \mathrm{C}$.

Laser damage threshold studies: The LDT measurement was made on the finely polished 4-methylpyridinium picrate crystal having thickness of $1 \mathrm{~mm}$. Experimentally, a Q-switched diode array side pumped Nd:YAG laser operating at $532 \mathrm{~nm}$ radiation was used for this study. Many shot LDT measurements were made on the well polished plane of the grown 4methylpyridinium picrate crystal. The beam spot size on the sample was $1 \mathrm{~mm}$ and input energy was measured as $350 \mathrm{~mJ}$. The energy density of the input laser beam was recorded using power meter till the crystal got damaged.

\section{RESULTS AND DISCUSSION}

X-ray diffraction analysis: Single crystal XRD analysis of 4-methylpyridinium picrate reveals that the crystal crystallizes in monoclinic crystal system with space group $\mathrm{P} 2{ }_{1}$. The asymmetric unit of the 4-methylpyridinium picrate consists of the four picrate anions and four pyridinium cations. The protonation on the $\mathrm{N}_{4}$ site of the cation is confirmed from $\mathrm{C}-\mathrm{N}$ bond distances and C-N-C bond angles. All the bond distances and bond angles of the four molecules in the asymmetric unit agreed with each other. In the crystal the cations are linked to anions via bifurcated $\mathrm{N}-\mathrm{H} \cdots(\mathrm{O}, \mathrm{O})$ hydrogen bonding which generating $\mathrm{R}_{1}{ }^{2}(6)$ graph motif. The $\mathrm{N}-\mathrm{H}$... O bonding is highly responsible for stability of the molecule. The torsion angles $\mathrm{C} 37-\mathrm{C} 38-\mathrm{C} 39-\mathrm{C} 40=179.2(5)^{\circ}$ and C42-C41-C39-C40 = $-179.5(5)^{\circ}$, which shows that the methyl group is in the +antiperiplanar (+ap) orientation with pyridinium ring. The dihedral angle between the pyridinium cations and picrate anions ring is $2.97^{\circ}$, which shows axial orientation between each other's [6-8].

Table- 1 shows the data and refinement of the X-ray crystal structure determination for this compound. Selected bond lengths and bond angles are presented in Table-2. ORTEP (Fig. 5) and the interaction of a single salt molecule view with numbering scheme in Fig. 4 and packing diagram (1 and 2) is shown in Figs. 2 and 3. The observed hydrogen bonds of 4-methylpyridinium picrate compound are summarized in Table- 3 .

TABLE-1

CRYSTALLOGRAPHIC AND STRUCTURE REFINEMENTS DATA OF 4-METHYLPYRIDINIUM PICRATE

\begin{tabular}{ll}
\hline Empirical formula & $\mathrm{C}_{28} \mathrm{H}_{24} \mathrm{~N}_{10} \mathrm{O}_{6}$ \\
Formula weight & 596.57 \\
Temperature & $293(2) \mathrm{K}$ \\
Wavelength & $0.71073 \AA$ \\
Crystal system, space group & Monoclinic, $\mathrm{P}_{1}$ \\
Unit cell dimensions & $\mathrm{a}=7.3088(1) \AA, \alpha=90^{\circ}$ \\
& $\mathrm{b}=24.886(1) \AA, \beta=90.567^{\circ}$ \\
& $\mathrm{c}=15.039(1) \AA, \gamma=90^{\circ}$ \\
Volume & $2735.3(2) \mathrm{A}^{3}$ \\
Z, Calculated density & $4,1.449 \mathrm{Mg} / \mathrm{m}^{3}$ \\
Absorption coefficient & $0.106 \mathrm{~mm}^{-1}$ \\
F(000) & 1240 \\
Crystal size & $0.30 \times 0.20 \times 0.20 \mathrm{~mm}$ \\
Theta range for data collection & 1.35 to $26.02^{\circ}$ \\
Limiting indices & $-8<=\mathrm{h}<=8 ;$ \\
& $-30<=\mathrm{k}<=30 ;$ \\
Reflections collected/unique & $-18<=1<=18$ \\
Completeness to $\theta=26.02$ & $39220 / 10699[\mathrm{R}(\mathrm{int})=0.0556]$ \\
Refinement method & $99.7 \%$ \\
Data/restraints/parameters & Full-matrix least-squares on $\mathrm{F}^{2}$ \\
Goodness-of-fit on $\mathrm{F}^{2}$ & $10699 / 1 / 824$ \\
Final R indices [I $>2 \sigma(\mathrm{I})]$ & 1.045 \\
R indices (all data) & $\mathrm{R} 1=0.0653, \mathrm{wR} 2=0.1527$ \\
Absolute structure parameter & $\mathrm{R} 1=0.1282, \mathrm{wR} 2=0.1935$ \\
Largest diff. peak and hole & $1.5(2)$ \\
\hline
\end{tabular}

FT-IR analysis: In 4-methylpyridinium picrate, there was a formation of strong hydrogen bond between 4-methylpyridine and picric acid. The anion donates from picric acid to pyridine moiety to form $\mathrm{N}^{+}-\mathrm{H}$ bond. The peak observed at $3434 \mathrm{~cm}^{-1}$ is due to N-H stretching vibrations (Fig. 6). The phenolic C-O stretching vibrations of picric acid is observed at $1297 \mathrm{~cm}^{-1}$. The peak observed at $3072 \mathrm{~cm}^{-1}$ corresponds to the aromatic $\mathrm{C}-\mathrm{H}$ stretching. The C-C stretching vibrations at $1589 \mathrm{~cm}^{-1}$ has been identified and assigned. The characteristic peak at 


\begin{tabular}{ll|lr}
\hline \multicolumn{5}{c}{ TABLE-2 } \\
\multicolumn{4}{c}{ SELECTED BOND DISTANCES (A) AND BOND } \\
\multicolumn{2}{c}{ ANGLES ( ${ }^{\circ}$ ) OF 4-METHYLPYRIDINIUM PICRATE } \\
\hline \multicolumn{2}{c}{ Bond distances } & \multicolumn{2}{c}{ Bond angles } \\
\hline $\mathrm{C}(7)-\mathrm{C}(8)$ & $1.382(1)$ & $\mathrm{C}(8)-\mathrm{C}(7)-\mathrm{C}(12)$ & $124.4(1)$ \\
$\mathrm{C}(7)-\mathrm{N}(5)$ & $1.447(1)$ & $\mathrm{N}(5)-\mathrm{C}(7)-\mathrm{C}(12)$ & $119.7(1)$ \\
$\mathrm{C}(7)-\mathrm{C}(12)$ & $1.452(1)$ & $\mathrm{C}(9)-\mathrm{C}(8)-\mathrm{C}(7)$ & $117.6(1)$ \\
$\mathrm{C}(8)-\mathrm{C}(9)$ & $1.367(1)$ & $\mathrm{C}(8)-\mathrm{C}(9)-\mathrm{C}(10)$ & $122.6(1)$ \\
$\mathrm{C}(9)-\mathrm{C}(10)$ & $1.378(1)$ & $\mathrm{C}(8)-\mathrm{C}(9)-\mathrm{N}(7)$ & $116.6(1)$ \\
$\mathrm{C}(9)-\mathrm{N}(7)$ & $1.432(1)$ & $\mathrm{C}(10)-\mathrm{C}(11)-\mathrm{C}(12)$ & $125.0(1)$ \\
$\mathrm{C}(10)-\mathrm{C}(11)$ & $1.352(1)$ & $\mathrm{C}(10)-\mathrm{C}(11)-\mathrm{N}(6)$ & $115.8(1)$ \\
$\mathrm{C}(11)-\mathrm{C}(12)$ & $1.431(1)$ & $\mathrm{N}(4)-\mathrm{C}(42)-\mathrm{C}(41)$ & $119.0(1)$ \\
$\mathrm{C}(11)-\mathrm{N}(6)$ & $1.462(1)$ & $\mathrm{C}(37)-\mathrm{C}(38)-\mathrm{C}(39)$ & $120.5(1)$ \\
$\mathrm{C}(12)-\mathrm{O}(1)$ & $1.244(1)$ & $\mathrm{O}(1)-\mathrm{C}(12)-\mathrm{C}(11)$ & $123.6(1)$ \\
$\mathrm{C}(37)-\mathrm{N}(4)$ & $1.339(1)$ & $\mathrm{O}(3)-\mathrm{N}(5)-\mathrm{O}(2)$ & $121.6(1)$ \\
$\mathrm{C}(37)-\mathrm{C}(38)$ & $1.364(1)$ & $\mathrm{O}(3)-\mathrm{N}(5)-\mathrm{C}(7)$ & $117.9(1)$ \\
$\mathrm{C}(38)-\mathrm{C}(39)$ & $1.376(1)$ & $\mathrm{N}(4)-\mathrm{C}(37)-\mathrm{C}(38)$ & $119.6(1)$ \\
$\mathrm{C}(39)-\mathrm{C}(41)$ & $1.382(1)$ & $\mathrm{O}(7)-\mathrm{N}(6)-\mathrm{O}(6)$ & $122.9(1)$ \\
$\mathrm{C}(39)-\mathrm{C}(40)$ & $1.491(1)$ & $\mathrm{O}(4)-\mathrm{N}(7)-\mathrm{O}(5)$ & $121.6(1)$ \\
$\mathrm{C}(41)-\mathrm{C}(42)$ & $1.362(1)$ & - & - \\
$\mathrm{C}(42)-\mathrm{N}(4)$ & $1.323(1)$ & - & - \\
$\mathrm{N}(4)-\mathrm{H}(4)$ & 0.8600 & & - \\
\hline
\end{tabular}

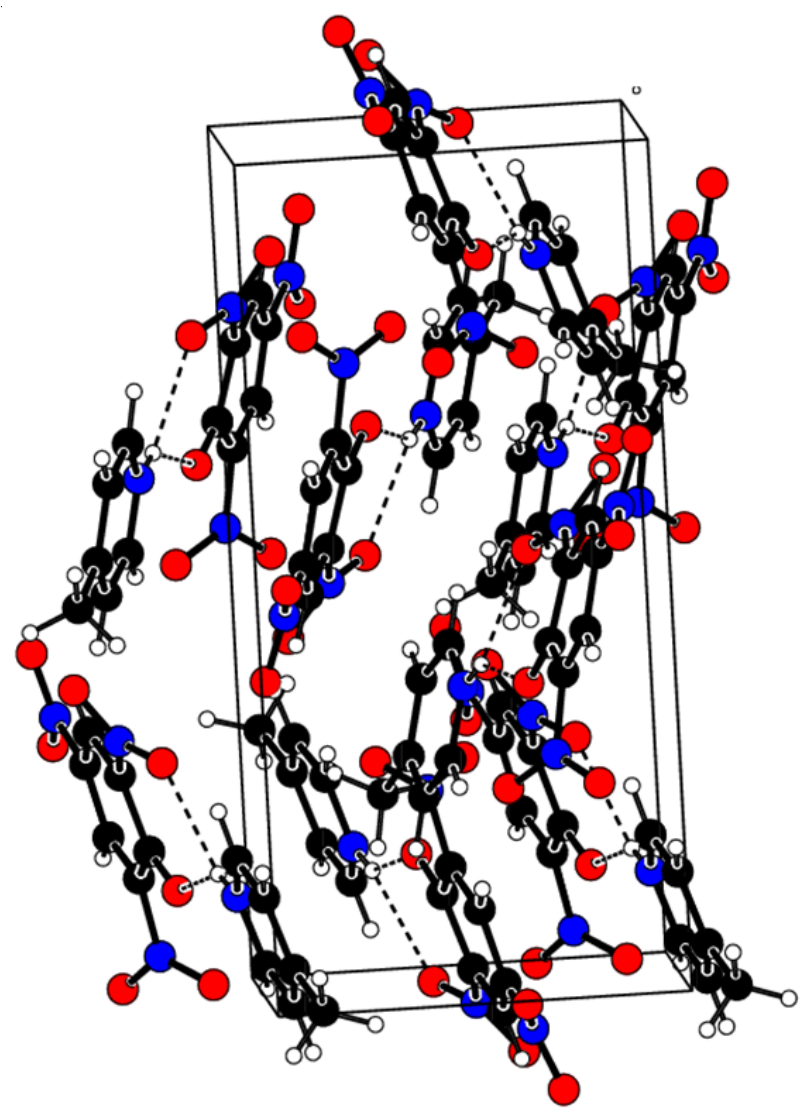

Fig. 2. Packing 1 for 4-methylpyridinium picrate

$1431 \mathrm{~cm}^{-1}$ is due to the ring stretching vibration of $\mathrm{C}=\mathrm{C}$ group. The asymmetric and symmetric stretching vibration of $\mathrm{NO}_{2}$ is observed at 1565 and $1338 \mathrm{~cm}^{-1}$. The ring stretching of $\mathrm{C}=\mathrm{N}$ group is observed at $1431 \mathrm{~cm}^{-1}$. The peak at $998 \mathrm{~cm}^{-1}$ due to the in-plane $\mathrm{C}-\mathrm{H}$ bending. The out-of-plane $\mathrm{C}-\mathrm{H}$ bending of aromatic compound is observed at $750 \mathrm{~cm}^{-1}$. The ring $\mathrm{C}=\mathrm{C}$ bending is observed at $709 \mathrm{~cm}^{-1}$. The peak at $522 \mathrm{~cm}^{-1}$ is due to $\mathrm{NO}_{2}$ rocking [9]. Table-4 shows FT-IR Spectral data of 4methylpyridinium picrate crystal.

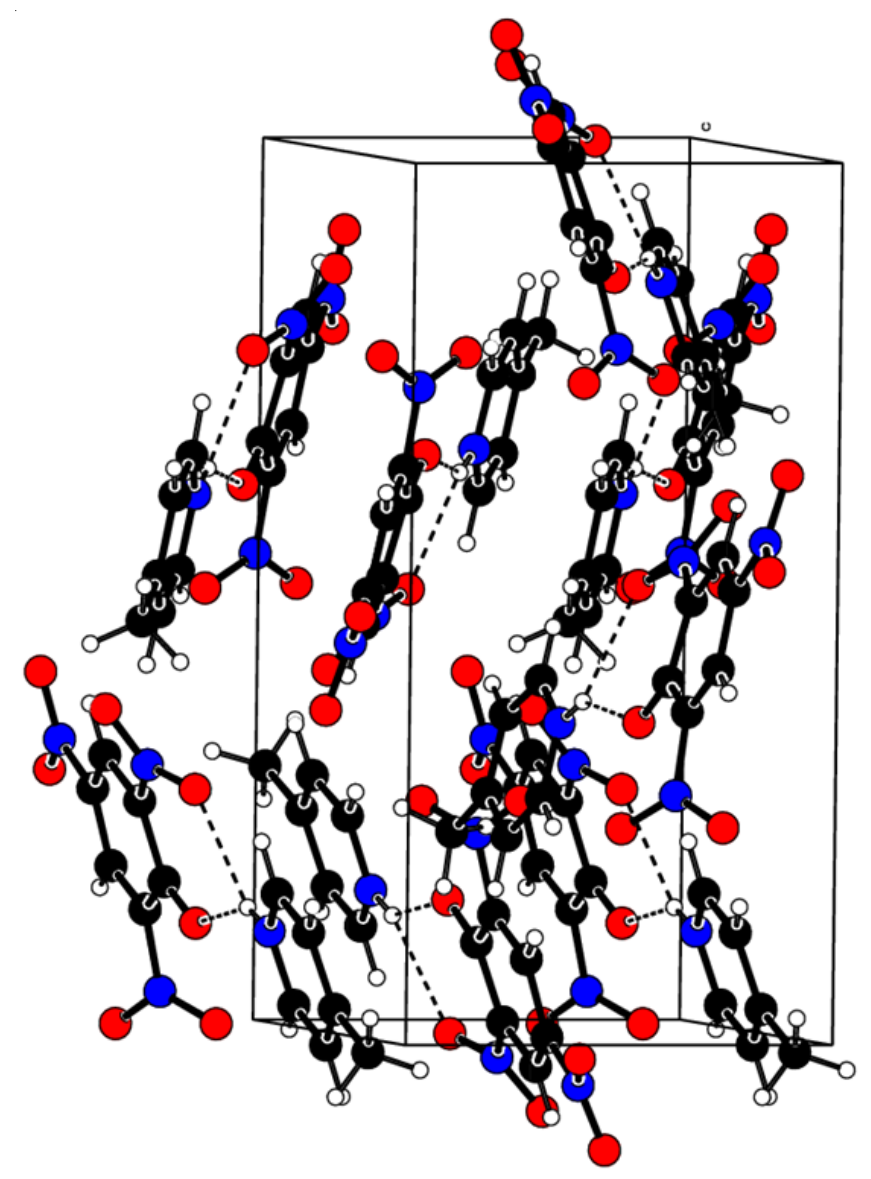

Fig. 3. Packing 2 for 4-methylpyridinium picrate

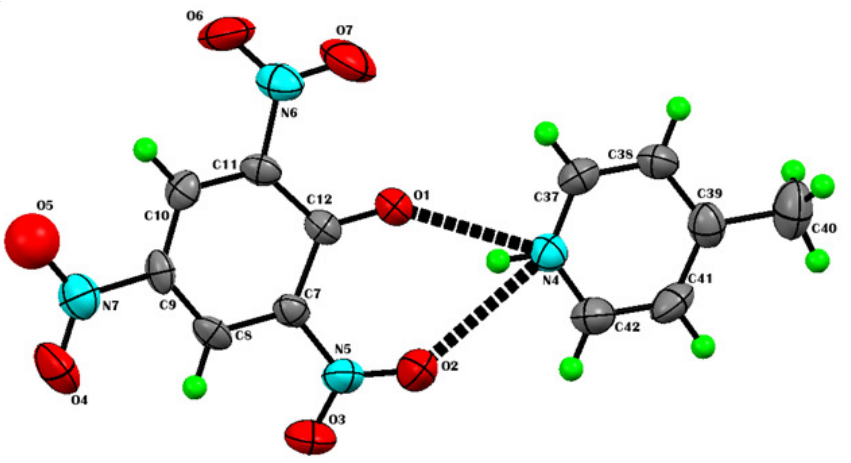

Fig. 4. Labeled diagram of 4-methylpyridinium picrate. Thermal ellipsoidal $50 \%$ probability level

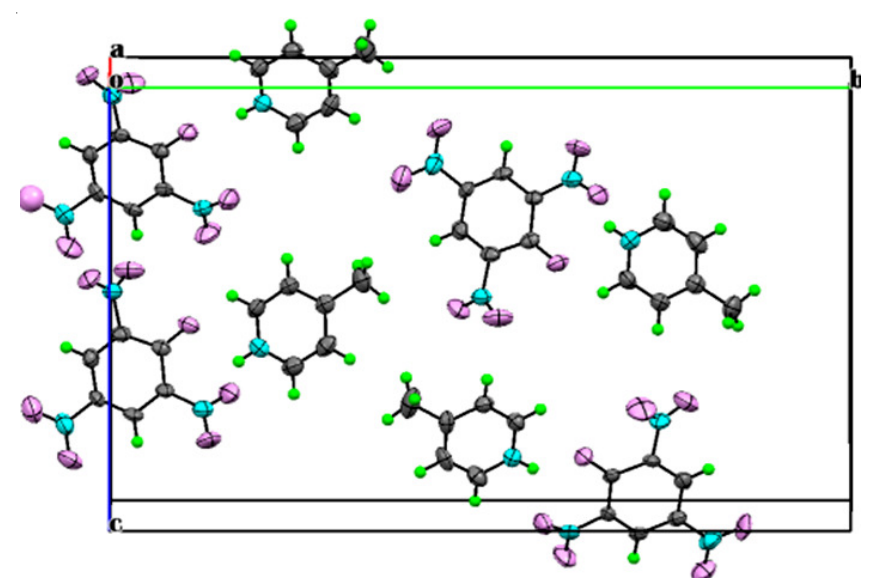

Fig. 5. ORTEP plot for 4-methylpyridinium picrate 


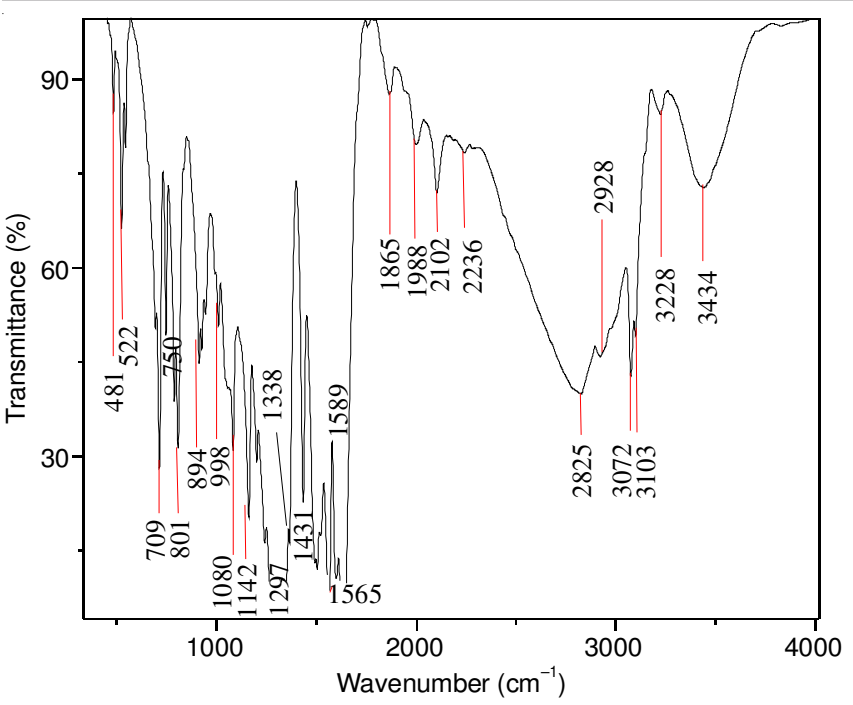

Fig. 6. FTIR spectrum of 4-methylpyridinium picrate

\begin{tabular}{|c|c|c|c|c|c|}
\hline \multicolumn{6}{|c|}{$\begin{array}{c}\text { TABLE-3 } \\
\text { HYDROGEN BONDS GEOMETRY OF } \\
\text { 4-METHYLPYRIDINIUM PICRATE }\end{array}$} \\
\hline \multicolumn{2}{|l|}{$\mathrm{D}-\mathrm{H} \cdots \mathrm{A}$} & $\begin{array}{l}\mathrm{d}(\mathrm{D}-\mathrm{H}) \\
(\AA)\end{array}$ & $\begin{array}{l}\mathrm{d}(\mathrm{H} \cdots \mathrm{A}) \\
(\AA)\end{array}$ & $\begin{array}{l}\mathrm{d}(\mathrm{D} \cdots \mathrm{A}) \\
(\AA)\end{array}$ & $\begin{array}{c}\angle(\mathrm{DHA}) \\
\left({ }^{\circ}\right)\end{array}$ \\
\hline \multirow{2}{*}{\multicolumn{2}{|c|}{$\begin{array}{l}\mathrm{N}(4)-\mathrm{H}(4) \cdots \mathrm{O}(1) \# 1 \\
\mathrm{~N}(4)-\mathrm{H}(4) \cdots \mathrm{O}(2) \# 1\end{array}$}} & 0.86 & 1.93 & $2.673(1)$ & 143.5 \\
\hline & & 0.86 & 2.22 & $2.883(1)$ & 134.3 \\
\hline \multicolumn{6}{|c|}{ Symmetry codes: $\mathrm{x}-1 / 2,-\mathrm{y}, \mathrm{z}+1 / 2 \# 1$} \\
\hline \multicolumn{6}{|c|}{$\begin{array}{c}\text { TABLE-4 } \\
\text { FT-IR SPECTRAL DATA OF 4-METHYLPYRIDINIUM PICRATE }\end{array}$} \\
\hline $\begin{array}{l}\text { Frequencies } \\
\left(\mathrm{cm}^{-1}\right)\end{array}$ & \multicolumn{5}{|c|}{ Assignment } \\
\hline 3434 & \multicolumn{5}{|c|}{$\mathrm{N}^{+}-\mathrm{H}$ stretching } \\
\hline 3072 & \multicolumn{5}{|c|}{$\mathrm{C}-\mathrm{H}$ stretching } \\
\hline 1297 & \multicolumn{5}{|c|}{ Phenolic C-O stretching vibrations of picric acid } \\
\hline 1589 & \multicolumn{5}{|c|}{ C-C stretching vibration } \\
\hline 1431 & \multicolumn{5}{|c|}{$\mathrm{C}=\mathrm{C}$ stretching vibration } \\
\hline $1565 \& 1338$ & \multicolumn{5}{|c|}{$\begin{array}{l}\text { Asymmetric and symmetric stretching vibrations of } \\
\mathrm{NO}_{2}\end{array}$} \\
\hline 998 & \multicolumn{5}{|c|}{ In-plane $\mathrm{C}-\mathrm{H}$ bending } \\
\hline 750 & \multirow{2}{*}{\multicolumn{5}{|c|}{ Out-of-plane $\mathrm{C}-\mathrm{H}$ bending of aromatic compound }} \\
\hline 522 & & & & & $\mathrm{NO}_{2}$ rocking \\
\hline
\end{tabular}

Thermal analysis:From TGA curve (Fig. 7) of 4-methylpyridinium picrate was observed to be at $171.50{ }^{\circ} \mathrm{C}$ with no weight loss. It is clear that there is no physically absorbed water content in the molecular structure of 4-methylpyridinium picrate compound. Since TGA curve shows a single stage weight loss due to decomposition of 4-methylpyridinium picrate into fragments and its subsequent volatilization. An endothermic peak is observed in DTA at $170.05{ }^{\circ} \mathrm{C}$ which is due to melting of the sample. Further it indicates that there is no phase transition before this melting point and also the grown crystal is free from solvent inclusion. Good crystalline nature of the 4-methylpyridinium picrate compound is clearly evident from the sharpness of the endothermic peak [10].

UV-Vis-NIR analysis: Fig. 8 shows the transmittance spectra of the grown crystal. When transmission is monitored from longer wavelength to shorter wavelength, hence there is no absorption between the regions from 900 to $435 \mathrm{~nm}$. The lower cut-off wavelength is found to be $435 \mathrm{~nm}$ and the

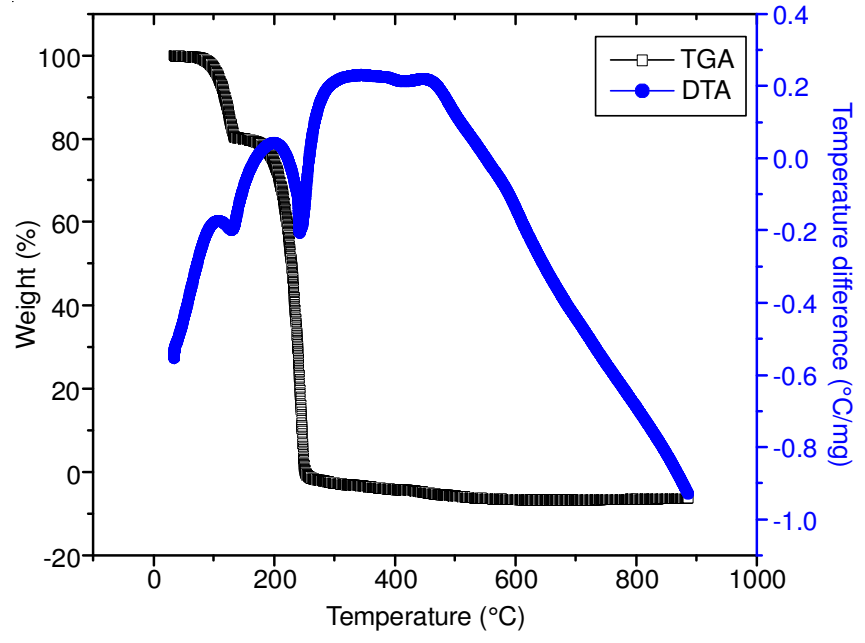

Fig. 7. TG-DTA curves for 4-methylpyridinium picrate

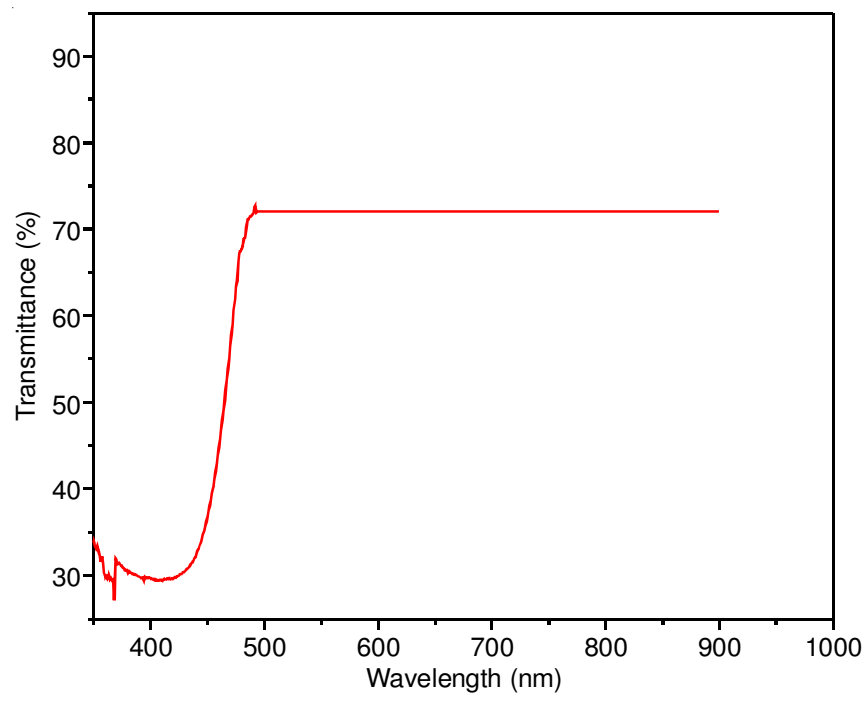

Fig. 8. UV-visible spectrum of 4-methylpyridinium picrate

percentage of transmittance is $72 \%$. An electron under impact by an incident photon is excited to middle state where it interacts with lattice vibrations and it reaches a final state, the entire result being the absorption of photons [11]. The absorption coefficient $(\alpha)$ was calculated from the transmission spectrum based on the following equation:

$$
\alpha=\frac{1}{\mathrm{t}} \log \left(\frac{1}{\mathrm{~T}}\right)
$$

where, $\mathrm{T}$ is the transmittance and ' $\mathrm{t}$ ' is the thickness of crystal.

It also ensures the crystal suitability for optical harmonic generation, optoelectronic device application [12].

Photoconductivity studies: Fig. 9 shows dark and photo currents dependence of field. It revealed that the dark current and photo current increase linearly with applied field. Hence, 4-methylpyridinium picrate crystal has more dark current than the photo current, called as negative photoconductivity. The negative photoconductivity in this case is due to the reduction of the number of charge carriers or their life time in the presence of radiation [13]. Life time decreases with illumination, could be due to the trapping process and increase in carrier velocity according to the relation, 


$$
\tau=(\mathrm{vsN})^{-1}
$$

where, $\mathrm{v}$ is the thermal velocity of the carriers, $\mathrm{s}$ is the capture cross section of the recombination centers and $\mathrm{N}$ is the carrier concentration [14]. As a result, the sample is kept under exposure to light, the recombination of electrons and holes take place, resulting in decrease in the number of mobile charge carriers, giving rise to negative photoconductivity.

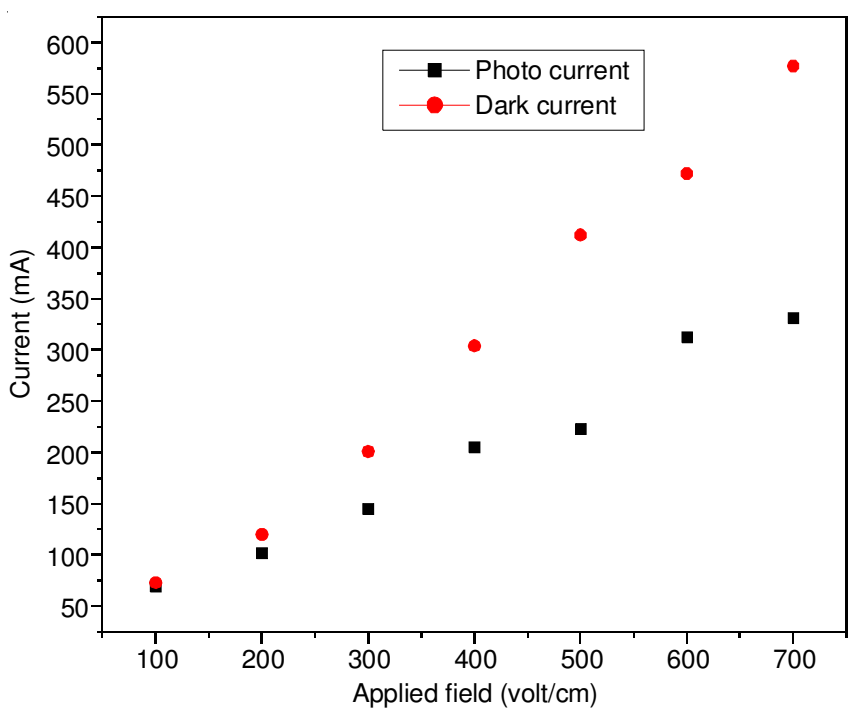

Fig 9. Variation of current with applied field for 4-methylpyridinium picrate crystal

Dielectric analysis: Figs. 10 and 11 shows the dielectric constant and dielectric loss for different frequencies. These curves proposed that the dielectric loss strongly depends on the frequency of applied field, similar to that of dielectric constant which is common for the ionic system of crystals $[15,16]$. In organic compound, the dielectric response is excellent in the lower frequency region and hence the experiments were carried out in the lower frequency region only. The dielectric constant $\left(\varepsilon_{\mathrm{r}}\right)$ was calculated using the following equations:

$$
\varepsilon_{\mathrm{r}}=\frac{\mathrm{C}_{\text {crys }}}{\mathrm{C}_{\text {air }}}
$$

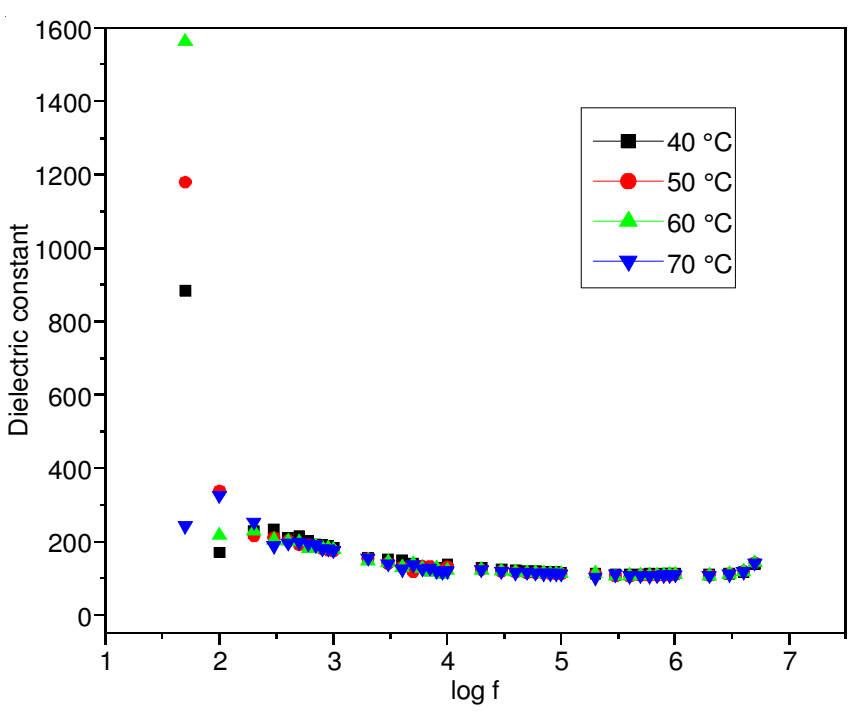

Fig. 10. Dielectric constant vs. frequency

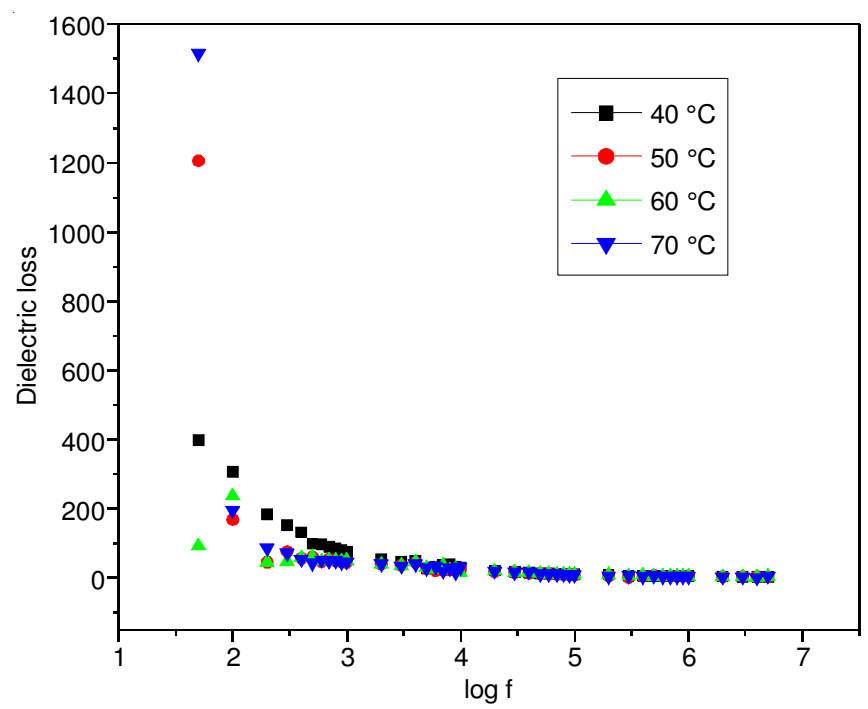

Fig. 11. Dielectric loss vs. frequency

$$
\varepsilon_{\mathrm{r}}=\frac{\mathrm{Ct}}{\varepsilon_{0} \mathrm{~A}}
$$

where, $\mathrm{C}$ is the capacitance; $\mathrm{t}$ is the thickness of the sample; $\varepsilon_{0}$ is the permittivity of the free space and $\mathrm{A}$ is the area of cross section.

The dielectric loss was calculated using the following relation:

$$
\varepsilon^{\prime \prime}=\varepsilon_{\mathrm{r}} \mathrm{D}
$$

where, $\mathrm{D}$ is the dissipation factor.

From the graph the dielectric constant decreases at high frequencies is recognized to the significant decrease in all the three polarizations such as orientation, electronic and ionic polarization and presence of space charge polarization near the grain boundry interface [17]. In 4-methylpyridinium picrate compound the value of dielectric constant at lower frequencies due to the excitation of the lattice vibrations and space charge polarization. The low value of dielectric constant at higher frequencies could be predictable to the declining of these polarizations slowly and contributed mainly by electronic polarization. The low dielectric loss at high frequency indicate that the grown 4-methylpyridinium picrate contains minimum defects $[18,19]$.

Laser damage threshold studies: The laser damage threshold depends upon the optical absorption, properties of materials, pulse width and specific heat, etc. If the laser damage threshold will be high, the material has high specific heat. If the material has a low laser damage threshold it strictly restricts its applications, like high optical transmittance [20]. The laser damage mainly occurs due to strain induced fractures caused by ionization processes and multi-photon absorption. The surface damage threshold of the crystal was calculated using the formula:

$$
\text { Power density }(\mathrm{d})=\mathrm{E} / \tau \mathrm{A}
$$

where, E is the energy $(\mathrm{mJ}), \tau$ is the pulse width (ns) and A is the area of the circular spot size. The calculated laser damage threshold is $6.96 \mathrm{GW} / \mathrm{cm}^{2}$. The LDT value of 4-methyl-pyridinium picrate crystal was high when compared to already report materials and the comparison value is shown in Table-5. Hence, 


\begin{tabular}{|c|c|c|}
\hline \multicolumn{3}{|c|}{$\begin{array}{c}\text { TABLE-5 } \\
\text { COMPARISON OF LASER DAMAGE THRESHOLD } \\
\text { VALUE WITH WELL-KNOWN CRYSTALS }\end{array}$} \\
\hline Crystal name & $\begin{array}{l}\text { LDT value } \\
\left(\mathrm{GW} / \mathrm{cm}^{2}\right)\end{array}$ & Ref. \\
\hline Benzimidazole by SEST & 1.71 & [21] \\
\hline Benzimidazole by VBT & 2.86 & [21] \\
\hline 2-Aminopyridinium succinate succinic acid & 0.80 & [22] \\
\hline 3-Br-4'-Methoxychalcone & 0.90 & [23] \\
\hline 4-Methylpyridinium 4-hydroxybenzoate & 5.41 & [24] \\
\hline 4-Methylpyridinium picrate & 6.96 & $\begin{array}{c}\text { Present } \\
\text { work }\end{array}$ \\
\hline
\end{tabular}

it is clear that the grown 4-methylpyridinium picrate crystal with high LDT value can be used for high-power laser device fabrications.

\section{Conclusion}

Crystals of 4-methylpyridinium picrate were grown by slow evaporation solution growth technique and the monoclinic crystal system was confirmed in the single XRD studies. Functional groups were identified by analyzing infrared spectrum and the impacts of hydrogen bonds on the vibration of functional groups were studied. Thermal analysis confirms that the crystal is stable upto $170.50{ }^{\circ} \mathrm{C}$. Optical studies shows the transparency nature of the crystal and it enhances the suitability of the material for opto-electronic applications. The photocurrent was less than the dark current signifying negative photoconducting nature. The low dielectric constant at higher frequency region indicates that the grown material is appropriate for electro optic applications. High value of laser damage threshold was measured.

\section{ACKNOWLEDGEMENTS}

One of the authors (D. Jayalakshmi) is grateful to the University Grants Commission, New Delhi, India for support under minor research project scheme.

\section{REFERENCES}

1. X.-T. Wu and L. Chen, Structure-Property Relationships in Non-Linear Optical Crystals II, Springer, vol. 145 (2012).

2. P.V. Dhanaraj, N.P. Rajesh, G. Vinitha and G. Bhagavannarayana, Mater. Res. Bull., 46, 726 (2011);

https://doi.org/10.1016/j.materresbull.2011.01.013.
3. N.C. Khalib, K. Thanigaimani, S. Arshad and I.A. Razak, Acta Crystallogr. Sect. E Struct. Rep. Online, 69, o1120 (2013); https://doi.org/10.1107/S1600536813016310.

4. M.A. Rajkumar, N.N. Mohideen, S.S.J. Xavier, S. Anbarasu and D.P.A. Devarajan, Acta Crystallogr. Sect. E Struct. Rep. Online, 71, 231 (2015); https://doi.org/10.1107/S2056989015000365.

5. F. Brody and P.R. Ruby, in ed.: E. Klingsberge, Pyridine and its Derivatives, Interscience, New York, vol. 114, p. 289 (1960).

6. Bruker, APEX2, SAINT, XPREP and SADABS Bruker AXS Inc, Madison, Wisconsin, USA (2004).

7. G.M. Sheldrick, SHELXS97 and SHELXL97, University of Gottingen, Germany (1997).

8. G.M. Sheldrick, Acta Crystallogr. A, 64, 112 (2008); https://doi.org/10.1107/S0108767307043930.

9. R.M. Silverstein, G.C. Bassler and T.C. Morrill, Spectrometric Identification of Organic Compounds, Wiley, New York (1991).

10. A.S.H. Hameed, G. Ravi, R. Dhanasekaran and P. Ramasamy, J. Cryst. Growth, 212, 227 (2000); https://doi.org/10.1016/S0022-0248(99)00896-9.

11. M. Mersch, K. Buse, W. Sauf, H. Hesse and E. Kratzig, Phys. Status Solidi, 140, 273 (1993); https://doi.org/10.1002/pssa.2211400127.

12. D.D.O. Eya, A.J. Ekpunobi and C.E. Okeke, Acad. Open Internet J., 17, 1 (2006).

13. R.H. Bube, Photoconductivity of Solids, Wiley, New York (1981).

14. I.M. Ashraf, H.A. Elshaikh and A.M. Badr, Cryst. Res. Technol., 39, 63 (2004); https://doi.org/10.1002/crat.200310150.

15. K.V. Rao and A. Smakula, J. Appl. Phys., 36, 2031 (1965); https://doi.org/10.1063/1.1714397.

16. K.V. Rao and A. Smakula, J. Appl. Phys., 37, 319 (1966); https://doi.org/10.1063/1.1707834.

17. G. Prabagaran, S. Arulmozhi, M.D. Raja and J. Madhavan, IOSR J. Appl. Phys., 2, 51 (2013).

18. K.B.R. Varma, K.B. Ramanaiah and K.V. Rao, Bull. Mater. Sci., 5, 39 (1983); https://doi.org/10.1007/BF02822348.

19. P. Rajesh and P. Ramasamy, J. Cryst. Growth, 311, 3491 (2009); https://doi.org/10.1016/j.jcrysgro.2009.04.020.

20. J.A. Brant, D.J. Clark, Y.S. Kim, J.I. Jang, A. Weiland and J.A. Aitken, Inorg. Chem., 54, 2809 (2015); https://doi.org/10.1021/ic502981r.

21. N. Vijayan, G. Bhagavannarayana, R. Ramesh Babu, R. Gopalakrishnan, K.K. Maurya and P. Ramasamy, Cryst. Growth Des., 6, 1542 (2006); https://doi.org/10.1021/cg060002g.

22. M. Magesh, G. Bhagavannarayana and P. Ramasamy, Spectrochim. Acta Mol. Biomol. Spectrosc, 150, 765 (2015); https://doi.org/10.1016/j.saa.2015.05.077.

23. P.S. Patil, S.M. Dharmaprakash, K. Ramakrishna, H.-K. Fun, R.S.S. Kumar and D.N. Rao, J. Cryst. Growth, 303, 520 (2007); https://doi.org/10.1016/j.jcrysgro.2006.12.068.

24. S. Sudhahar, M.K. Kumar, B.M. Sornamurthy and R.M. Kumar, Spectrochim. Acta Part A: Mol. Biomol. Spectrosc., 118, 929 (2014); https://doi.org/10.1016/j.saa.2013.09.072. 